\title{
Integrated treatment of hepatitis $C$ virus infection among people who inject drugs: study protocol for a randomised controlled trial (INTRO-HCV)
}

Lars T. Fadnes ${ }^{1,2^{*}}$ (D), Christer Frode Aas ${ }^{1,2}$, Jørn Henrik Vold ${ }^{1,2}$, Christian Ohldieck', Rafael Alexander Leiva ${ }^{3}$, Fatemeh Chalabianloo ${ }^{1,2}$, Svetlana Skurtveit ${ }^{4,5}$, Ole Jørgen Lygren ${ }^{1,6}$, Olav Dalgård ${ }^{7,8}$, Peter Vickerman ${ }^{9}$, Håvard Midgard ${ }^{10}$, Else-Marie Løberg ${ }^{1,11,12}$, Kjell Arne Johansson ${ }^{1,2}$ and for the INTRO-HCV Study Group

\begin{abstract}
Background: A large proportion of people who inject drugs (PWID) living with hepatitis C virus (HCV) infection have not been treated. It is unknown whether inclusion of HCV diagnostics and treatment into integrated substance use disorder treatment and care clinics will improve uptake and outcome of HCV treatment in PWID. The aim is to assess the efficacy of integrating HCV treatment to PWID and this paper will present the protocol for an ongoing trial.

Methods: INTRO-HCV is a multicentre, randomised controlled clinical trial that will compare the efficacy of integrated treatment of HCV in PWID with the current standard treatment. Integrated treatment includes testing for HCV, assessing liver fibrosis with transient elastography, counselling, treatment delivery, follow-up and evaluation provided by integrated substance use disorder treatment and care clinics. Most of these clinics for PWID provide opioid agonist therapy while some clinics provide low-threshold care without opioid agonist therapy. Standard care involves referral to further diagnostics, treatment and treatment follow-up given in a hospital outpatient clinic with equivalent medications. The differences between the delivery platforms in the two trial arms involve use of a drop-in approach rather than specific appointment times, no need for additional travelling, less blood samples taken during treatment, and treatment given from already known clinicians. The trial will recruit approximately $200 \mathrm{HCV}$ infected individuals in Bergen and Stavanger, Norway. The primary outcomes are time to treatment initiation and sustained virologic response, defined as undetectable HCV RNA 12 weeks after end of treatment. Secondary outcomes are cost-effectiveness, treatment adherence, changes in quality of life, fatigue and psychological wellbeing, changes in drug use, infection related risk behaviour, and risk of reinfection. The target group is PWID with HCV diagnosed receiving treatment and care within clinics for PWID.
\end{abstract}

Discussion: This study will inform on the effects of an integrated treatment program for HCV in clinics for PWID compared to standard care aiming to increase access to treatment and improving treatment adherence. If the integrated treatment model is found to be safe and efficacious, it can be considered for further scale-up.

Trial registration: ClinicalTrials.gov.no. NCT03155906.

Keywords: Chronic hepatitis C, Opiate substitution treatment, Integrated health care, Substance abuse treatment centres

\footnotetext{
* Correspondence: lars.fadnes@uib.no

${ }^{1}$ Bergen Addiction Research Group, Department of Addiction Medicine,

Haukeland University Hospital, Bergen, Norway

${ }^{2}$ Department of Global Public Health and Primary Care, University of Bergen,

Bergen, Norway

Full list of author information is available at the end of the article
}

(c) The Author(s). 2019 Open Access This article is distributed under the terms of the Creative Commons Attribution 4.0 International License (http://creativecommons.org/licenses/by/4.0/), which permits unrestricted use, distribution, and reproduction in any medium, provided you give appropriate credit to the original author(s) and the source, provide a link to the Creative Commons license, and indicate if changes were made. The Creative Commons Public Domain Dedication waiver (http://creativecommons.org/publicdomain/zero/1.0/) applies to the data made available in this article, unless otherwise stated. 


\section{Background}

Hepatitis $\mathrm{C}$ virus (HCV) is endemic among people who inject drugs (PWID) [1]. Globally $40 \%$ of the HCV disease burden is attributable to injecting drug use and in Western Europe this fraction is 64\%. Recently, highly effective direct-acting antiviral (DAA) treatment of $\mathrm{HCV}$ infection became available, prompting the World Health Organisation (WHO) to develop a global strategy to eliminate HCV by 2030. However, as PWID represent the majority of $\mathrm{HCV}$ patients in high income countries there are challenges particular to this group that must be addressed if elimination is to be achieved [2].

Chronic HCV infection is a slowly progressive disease that may lead to liver cirrhosis and subsequent complications, including hepatocellular carcinoma (HCC), liver failure and early deaths $[3,4]$. Among $\mathrm{HCV}$-infected people with opioid dependence, one-third develops advanced liver disease within three decades [5] and within this group, liver disease and drug overdose becomes equally common causes of death among individuals over the age of 50 years [6]. Reports from opioid agonist therapy (OAT) clinics in Norway indicate that more than half of patients receiving OAT have chronic HCV infection [7]. This represents an ageing cohort often at high risk of developing advanced liver disease [8]. Ongoing injecting risk behaviour with risk of onwards HCV transmission is also prevalent in this population [9]. Thus, reaching these individuals with $\mathrm{HCV}$ treatment is of critical importance both to reduce $\mathrm{HCV}$ disease burden and $\mathrm{HCV}$ transmission.

Until 2014, HCV treatment was interferon-based with low efficacy, considerable adverse effects and accordingly low treatment uptake particularly among PWID [10]. The perceived high risk of reinfection following successful treatment may also have represented a barrier to $\mathrm{HCV}$ treatment in this population [9]. The current availability of tolerable and highly efficient all-oral DAA treatment has changed the HCV care paradigm and led to significant therapeutic optimism. However, The World Hepatitis Summit in 2017 expressed concern for the lack of integrated approaches, acknowledging the need for new models of patient-centred service delivery and recognised the need for integrated collaborative approaches [11]. To achieve this, new models of care must be developed. Models focusing on interdisciplinarity, availability and accessibility, with decentralised clinics and frequent followups have been suggested to be effective [12-14]. However, reviews have called for further evidence on the effect of integrated treatment for people with substance use disorders $[15,16]$.

In Western Norway, more specifically in the cities of Stavanger and Bergen, OAT treatment is administered in an integrated treatment and care model with followup by physicians, nurses, social workers and psychologists on nearly a daily basis with observed intake of
OAT medications [17]. PWID not receiving OAT are offered care at municipal low-threshold health and care clinics. Thus, the models already in place could be a well-suited platform to evaluate the effect of integrated HCV care to PWID.

\section{Objectives}

This paper presents the protocol of the INTRO-HCV study. The primary objective of the INTRO-HCV study is to compare the efficacy of integrated treatment of $\mathrm{HCV}$ in PWID with the current standard treatment. Integrated treatment includes testing for $\mathrm{HCV}$, assessing liver fibrosis with transient elastography, counselling, treatment delivery, follow-up and evaluation provided by integrated substance use disorder treatment and care clinics. Most of these clinics for PWID provide OAT while some clinics provide low-threshold care without OAT. Standard care involves referral to further diagnostics, treatment and treatment follow-up given in a hospital outpatient clinic with equivalent medications.

Secondary objectives are comparison of treatment adherence between the integrated and standard arms, assessment of changes in quality of life, fatigue and psychological well-being before and after HCV treatment, as well as changes in drug use, infection related risk behaviour, and risk of reinfection among those with sustained virologic response (SVR). Further, we will estimate cost-effectiveness of integrated $\mathrm{HCV}$ care and incidence and prevalence of HCV infection among PWID in Bergen and Stavanger to assess population effects of scaling up treatment.

\section{Methods}

Study design

This is a multicentre, randomised controlled clinical trial.

\section{Study settings and participants}

The target group will be PWID receiving integrated substance use disorder treatment and care from involved clinics in Bergen and Stavanger who are chronically infected with $\mathrm{HCV}$ and eligible for treatment according to national guidelines.

Department of Addiction Medicine at Haukeland University Hospital in Bergen have adopted an integrated treatment and care model for PWID receiving OAT. In Bergen, OAT outpatient clinics have been established in each district where the patients are followed up by health and social workers on a nearly daily basis with observed intake of the OAT medications such as buprenorphine or methadone [17]. Every month, the OAT clinics have a total of 6000 visits among the approximately 500 patients. This group of patients have a large morbidity burden and have to a limited extent been able 
to get access to other standard health care. Each of the OAT outpatient clinics is staffed by a consultant and a physician/ specialist registrar in addiction medicine in addition to nurses, social workers, and psychologists. A close collaboration has been established between the Department of Addiction Medicine and the Agency for addiction and mental health in Bergen municipality, who is responsible for the care in several of the primary health clinics for PWID in Bergen. Clinics for PWID in the Stavanger area have a relatively similar structure and are responsible for the OAT treatment of approximately 460 patients within their area. People receiving OAT in Norway are generally prescribed buprenorphine or methadone, to some degree additional benzodiazepines but rarely other opioids. The treatment model in Bergen and Stavanger is a well-suited platform to test integration of $\mathrm{HCV}$ treatment aiming to improve the health and life span of a vulnerable group, and at the same time gathering knowledge which traditionally have been difficult to obtain.

\section{Eligibility criteria}

For the randomised trial, inclusion will be based on the following criteria

- PWID receiving OAT or low-threshold care from an included clinic with follow-up on weekly basis

- Chronically infected with HCV (HCV RNA positive measured at least twice over 6 months)

- Eligible for treatment according to national guidelines (criteria specified below)

- Giving informed consent

Enrolment started May 2017. At that time, eligibility for treatment according to Norwegian guidelines was defined as follows:

- Genotype 1 and 4 infection independent of stage of liver fibrosis.

- Genotype 2 and 3 infection with significant liver fibrosis.

Transient elastography (FibroScan) will be used in the screening of significant fibrosis defined as measurements above $7.0 \mathrm{kPa}[18,19]$.

Thus, some patients needed to wait some months after HCV diagnosis before initiating treatment. From 1st of February 2018, all patients with chronic HCV were eligible for treatment according to the updated national (independent of stage of liver fibrosis).

The following exclusion criteria will be used:

- HIV co-infection
- Severe extrahepatic HCV manifestations (e.g. cryoglobulinemia)

- Membranoprolifereative glomerulonephritis (MPGN) or renal failure (estimated glomerular filtration rate $<30 \mathrm{ml} / \mathrm{min} / 1.73 \mathrm{~m}^{2}$ )

- Decompensated liver disease (Child-Pugh score $>6$ points, class $\mathrm{B}$ and $\mathrm{C}$ )

Encephalopathy in Child-Pugh will be assessed according to the West Haven criteria [20].

- Currently receiving treatment for $\mathrm{HCV}$

\section{Interventions}

Participants randomised to standard care are first assessed and diagnosed at the integrated care clinics for PWID by nurse and physician and when found in need of treatment, are referred to a hospital clinic for further assessment and treatment. The standard care generally involves being referred to the medical outpatient clinic. The clinic will send a letter informing on time of appointment usually some weeks later and could involve some additional blood samples and imaging before initiating DAA treatment. Subsequently, an electronic prescription is given in a consultation where treatment is initiated. The medications given are in principle equivalent in the two trial arms. Most will receive medication combinations of either elbas$\mathrm{vir} /$ grazoprevir 50/100 mg or sofosbuvir/ledipasvir 400/90 $\mathrm{mg}$ (for genotype 1 and 4) or sofosbuvir/velpatasvir 400/ $100 \mathrm{mg}$ (for genotype 2 and 3) - sometimes also in combination with voxilaprevir $100 \mathrm{mg}$ or ribavirin $200 \mathrm{mg}$ due to specific clinical indications. Glecaprevir/pibrentasvir $100 / 40 \mathrm{mg}$ may also be used in special cases. Patients are generally given follow-up consultations every 4 weeks during treatment and a post-treatment assessment 12 weeks after completed treatment. Typically, this involves a total of 4-5 consultation visits at the hospital.

Participants randomised to integrated treatment are given integrated assessment and treatment at the clinics for PWID (by nurse and physician). For those found to be in need of treatment, medications are made available by a nurse that gives follow-up for OAT or lowthreshold care for PWID. Follow-up during treatment is given in parallel with delivery of OAT treatment and other care. At 12 weeks post treatment, a research nurse takes blood samples to assess the treatment effect.

The differences between the delivery platforms in the two trial arms involve the following main aspects:

- Need of travel: Standard care involves transportation to a hospital clinic - a distance that ranges from 1 to about $25 \mathrm{~km}$ in distance (with potential travel costs) while integrated treatment does generally not require need for additional travel 
- Need to come to specific appointment times: Standard treatment is generally given based on appointments while integrated treatment is generally given in a drop-in approach

- Frequency of blood samples during treatment is mainly depending on clinical indication (e.g. suspected adverse effects or complications). Less blood sampling may reduce discomfort

- Time used and potential for overlapping appointments: For standard treatment there is a higher risk that the appointment time overlap with other important activity including other health care, while for integrated treatment appointment time is generally planned together with patient

- Need to meet new clinicians for health care: In integrated care clinics, follow-up is generally done by already familiar contact nurse and physician providing regular follow-up. Standard treatment is given in hospital clinic by clinicians often unfamiliar to the patients

\section{Outcomes}

Primary outcome measures are

- Sustained virologic response will be assessed by undetectable HCV RNA at 12 (range 10-14) weeks after completed treatment. The virologic blood samples in Bergen will be analysed at Department for microbiology (accredited by ISO-standard $15,189)$ after being centrifuged at each study clinic before transfer

- Time to treatment initiation after diagnosing HCV in need of treatment (in line with national guidelines). This will be assessed with time-to-event analyses. We also plan to present stratified analyses on patient-related delay and system-related delay

\section{Secondary outcome measures are}

- Treatment adherence assessed by proportion of doses observed being taken in intervention group and reported obtainment from pharmacies of the prescribed drugs combined with self-reported questions on adherence collected at 4, 8 (and 12 for treatment recommended beyond 8 weeks) weeks after treatment initiation. The self-reported questions categorise adherence during last four weeks into rarely, sometimes but less than half of the doses, between 50 and $80 \%$ of the doses, more than $80 \%$ of the doses, and always ( $95 \%$ of doses or more). These outcome measures will be collected at the OAT/PWID clinics

- Reinfection will be defined as HCV RNA recurrence following SVR. Incidence rates will be calculated using person-time techniques assuming a Poisson distribution. All patients achieving SVR will be assessed for reinfection 3 months after treatment and then annually. HCV RNA positive samples will be further analysed with a quantitative HCV RNA count, HCV genotyping. Relapse is defined as presence of the same virus strain at the time of diagnosis and at the end of treatment. Anti-HIV and use of other drugs will also be assessed

- Changes in quality of life will be assessed with the questionnaire EQ-5D-5 L (https://euroqol.org/eq-5dinstruments/) in addition to a self-reported question on happiness on a 0 to 10 scale at 12 weeks after treatment compared to before treatment

- Changes in fatigue will be assessed with the Fatigue Symptom Scale at 12 weeks after treatment compared to before treatment

- Changes in psychological well-being will be assessed with the Norwegian validated translation version of Hopkins Symptom Checklist (SCL-10) at 12 weeks after treatment compared to before treatment

- Assessment of changes in substance use will be assessed with self-reported use of the following drug categories the last 30 days, the last 12 months and ever: Alcohol, tobacco, cannabis, amphetamines, cocaine, heroin, other opioids not prescribed by physician, benzodiazepines or z-hypnotics, hallucinogens, solvents and gamma hydroxybutyrate (GHB), anabolic steroids and other drugs at 12 weeks after treatment compared to before treatment

- Assessment of changes in injecting risk behaviour will be performed with questions assessing sharing of needles and other user equipment before and after HCV treatment at 12 weeks after treatment compared to before treatment

- Health provider costs by using an ingredients approach, where quantities used and the value (or price) of each unit is estimated in the both trial arms. Health care costs will be used in a health economic evaluation, where both costs per cured patient and per Quality Adjusted Life Year (QALY) gained will be estimated.

\section{Sample size}

We expect higher rates of treatment success in the intervention arm receiving integrated treatment compared to the standard arm. The power calculation is based on the following assumptions:

- The power is set at $90 \%$ with a two-sided alpha $(\alpha)$ error of $5 \%$.

- Comparison of SVR at 12 weeks.

- Up to 33\% lost to follow-up at 12 weeks after treatment. 
- Equal proportions between the groups, 30\% higher rates of successfully cured in integrated compared to standard treatment (e.g. 50\% in the standard arm and $80 \%$ in the intervention arm).

- Statistical power calculations in Stata.

Based on these assumptions, 87 persons are required in intervention arm and 87 persons in the control arm. Reducing the differences in rates of successfully cured to $25 \%$ while reducing power to $80 \%$, 99 persons in each arm would be required (or 66 persons if assuming no lost-to-follow-up).

\section{Recruitment}

All PWID receiving OAT treatment or low-threshold care from included clinics will be considered the reference target population. As part of an annual clinical assessment, patients will be informed about the study and asked for consent to participation. All patients in target population will be offered annual clinical assessment and study participation. For those giving informed consent, an extended clinical assessment will be offered and those diagnosed with chronic HCV will be randomised for the intervention.

\section{Allocation and blinding}

We will use block randomisation with a 1:1 ratio using blocks of 10 to ensure relatively similar distribution between both arms throughout different time periods of the trial. Randomisation will be electronically registered. The randomisation will be stratified by site/county (site 1: Bergen/Hordaland and site 2: Stavanger/ Rogaland).

Even though complete blinding is regarded as difficult and would probably come at a cost of reduction in external validity [21], there will be some degree of blinding/ masking. Randomisation will be disclosed to physician and other health care staff providing treatment and follow-up for PWID, but not to research nurses conducting data collection for outcomes. Patients will be informed of which intervention arm they are randomised to and the form of follow-up they will receive, but not on other follow-up alternatives they do not receive and what the hypotheses for the study are.

\section{Data collection and management}

Data collection and follow-up will be given in line with Table 1 and Fig. 1.

The blood samples for the primary outcome measures will be collected at the OAT/PWID clinics for participants randomised to integrated care and at the hospital outpatient clinic for the participants randomised to standard care. However, for patients who do not come for assessment at the hospital clinic 12 weeks after treatment, efforts will be made to collect these blood samples at the OAT/PWID clinic. For the remaining outcome measures, these will be measured at the OAT/PWID clinics by research nurses through a structured interview for both participants randomised to standard and integrated treatment.

\section{Analyses and statistical methods}

A detailed plan for analysis will be developed before data export and analysis. We will in this section outline some of the principles which will be used to guide decisions during data analysis. Analysis methods will follow the CONSORT and SPIRIT guidelines as far as possible [2224]. All tests will be two-sided. Descriptive results and efficacy estimates will be presented with $95 \%$ confidence intervals. The statistical significance is set at $p<0.05$. Potential confounders may be considered for adjustment if they are imbalanced at baseline (with assumed meaningful differences). Missing data will be considered, and appropriate imputations based on pre-defined assumptions will be done when necessary (as described in detailed plan of analysis). Categorical variables will be summarized as percentages and continuous variables as medians with interquartile ranges or means with standard deviation for variables with a Gaussian distribution. The main outcomes will be analysed with time-to-event analysis (Cox regression and Kaplan-Meier plots) and generalised linear models/logistic regression. A separate health economic evaluation will assess the incremental cost-effectiveness ratio of the intervention arm compared to the control arm. A Markov model will be used, and the analysis will be exhibited in TreeAge. Results will be presented as cost per QALYs of integrated versus standard HCV care.

\section{Potential harms and data monitoring}

Those who participate in the study will be randomised to one of two different follow-up programs. It is possible that the treatment follow-up in the integrated treatment is inferior in quality to the standard treatment. Several measures have been taken to ensure sufficient quality of the treatment follow-up and to safeguard through detection of potential severe adverse effects (SAEs). It is also possible that the integrated treatment will lead to better treatment adherence and response and thus less morbidity.

There is a risk of hepatic decompensation during treatment of patients with cirrhosis and portal hypertension [25]. To reduce this risk, patients with decompensated cirrhosis (Child Pugh class C or D) will be excluded. Further, there is a small risk of reactivation of hepatitis $B$ virus among patients with occult infection after treatment for $\mathrm{HCV}$ and potentially liver failure unless properly assessed [26]. However, patients with a possible occult hepatitis B infection (anti-HBc positive, anti-HBs negative and $\mathrm{HBsAg}$ negative) will be closely followed up by weekly blood sampling during the first 4 weeks of treatment including liver 
Table 1 Flow chart of the study outlining follow-up visits and assessments at each visit

\begin{tabular}{|c|c|c|c|c|c|c|c|c|}
\hline & $\begin{array}{l}\text { Screening } \\
1 \text { (part 1) }\end{array}$ & $\begin{array}{l}\text { Screening } \\
2 \text { (part 2) }\end{array}$ & $\begin{array}{l}\text { Treatment initiation } \\
\text { or referral to standard } \\
\text { treatment (physician) }\end{array}$ & $\begin{array}{l}\text { Treatment } \\
\text { follow-up ( } 4 \text { weeks } \\
\text { after initiation) }\end{array}$ & $\begin{array}{l}\text { Treatment } \\
\text { follow-up ( } 8 \\
\text { weeks after } \\
\text { initiation) }\end{array}$ & $\begin{array}{l}\text { Treatment } \\
\text { follow-up } \\
\text { (12 weeks } \\
\text { after } \\
\text { initiation) }\end{array}$ & $\begin{array}{l}\text { Effect } \\
\text { assessment } \\
\text { (12 weeks } \\
\text { after } \\
\text { completion) }\end{array}$ & $\begin{array}{l}\text { Annual } \\
\text { follow- } \\
\text { up }\end{array}$ \\
\hline $\begin{array}{l}\text { Acceptable time shift } \\
\text { (days) }\end{array}$ & & & & \pm 7 & \pm 7 & \pm 7 & \pm 14 & \pm 60 \\
\hline Physician assessment & & & $x$ & & & & $x$ & $x$ \\
\hline $\begin{array}{l}\text { Research nurse } \\
\text { assessment }\end{array}$ & $x$ & $x$ & & & & & $x$ & $x$ \\
\hline - Informed consent & $x$ & & & & & & & \\
\hline - Eligibility assessment & $x$ & $x$ & $x$ & & & & & \\
\hline $\begin{array}{l}\text { - Follow-up by staff deliv- } \\
\text { ering treatment and pro- } \\
\text { viding information } \\
\text { (several times weekly) }\end{array}$ & & & $x$ & $x$ & $x$ & $x$ & & \\
\hline - Clinical assessment & $x$ & $x$ & b & b & b & b & & $x$ \\
\hline $\begin{array}{l}\text { - Counselling on } \\
\text { prevention }\end{array}$ & & & $x$ & $x$ & $x$ & $x$ & $x$ & $x$ \\
\hline Elastography $^{a}$ & & $x$ & & & & & $(X)$ & $x$ \\
\hline \multicolumn{9}{|l|}{ Lab tests } \\
\hline - Viral testing & $x$ & & & & & & $x$ & $x$ \\
\hline $\begin{array}{l}\text { Full blood count and } \\
\text { transaminases }\end{array}$ & $x$ & & & b & b & b & $x$ & $x$ \\
\hline HSCL-10 (mental health) & $x$ & & & & & & $x$ & $x$ \\
\hline FAS (fatigue symptoms) & $x$ & & & & & & $x$ & $x$ \\
\hline EQ-5D-5 L (quality of life) & $x$ & & & & & & $x$ & $x$ \\
\hline Infection risk behaviour & $x$ & & & & & & $x$ & $x$ \\
\hline Substance use patterns & $x$ & & & & & & $x$ & $x$ \\
\hline $\begin{array}{l}\text { HCV genotyping and viral } \\
\text { load }\end{array}$ & $x$ & & & & & & $x$ & $x$ \\
\hline
\end{tabular}

${ }^{a}$ Elastography after treatment will be assessed in Bergen and not in Stavanger due to elastography availability only in hospital clinic and not outpatient clinic ${ }^{\mathrm{b}}$ Additional tests will be taken on clinical indication

enzyme assessments and HBV DNA (PCR) in order to being able to identifying reactivation in early stages.

All grade 3 and 4 adverse effects are considered as SAE and will be reported as such. For the evaluation of safety, all SAEs occurring during the trial follow-up period will be reported on the Clinical Report Form using a national registration form for medication related side effects. A copy of the form will be sent to RELIS Vest in addition to a copy sent to the clinical coordinators and steering committee reviewing all cases. Adverse effects grade 1 or 2 will be assessed through a questionnaire.

All SAEs will be followed until resolution or until a stable clinical end-point is reached. All measures required for SAE management and the ultimate outcome of the SAE will be recorded.

Similarly, there is potentially a risk for development of $\mathrm{HCV}$ resistant to direct acting antiviral medications, particularly among patients not completing treatment. Efforts will be made to avoid treatment failure and aiming for a secondary curative treatment among those failing first treatment. There will not be an independent data monitoring committee. The study coordination unit will be responsible to ensure adherence to the protocol, quality of the study and ethical conduct.

\section{Discussion}

The research project will improve knowledge on the impact on health care organisation and structure on patient outcomes. We will assess a platform aiming for easier access to treatment of $\mathrm{HCV}$ among PWID who have been difficult to reach with ordinary health services. Integrated treatment models may be an opportunity to increase adherence to $\mathrm{HCV}$ treatment and evaluate collaborative care in light of access to direct acting antiviral medications. The treatment platform could reduce the burden of HCV among this patient population and could contribute to $\mathrm{HCV}$ elimination. We will test this with a randomised controlled trial done in parallel with 


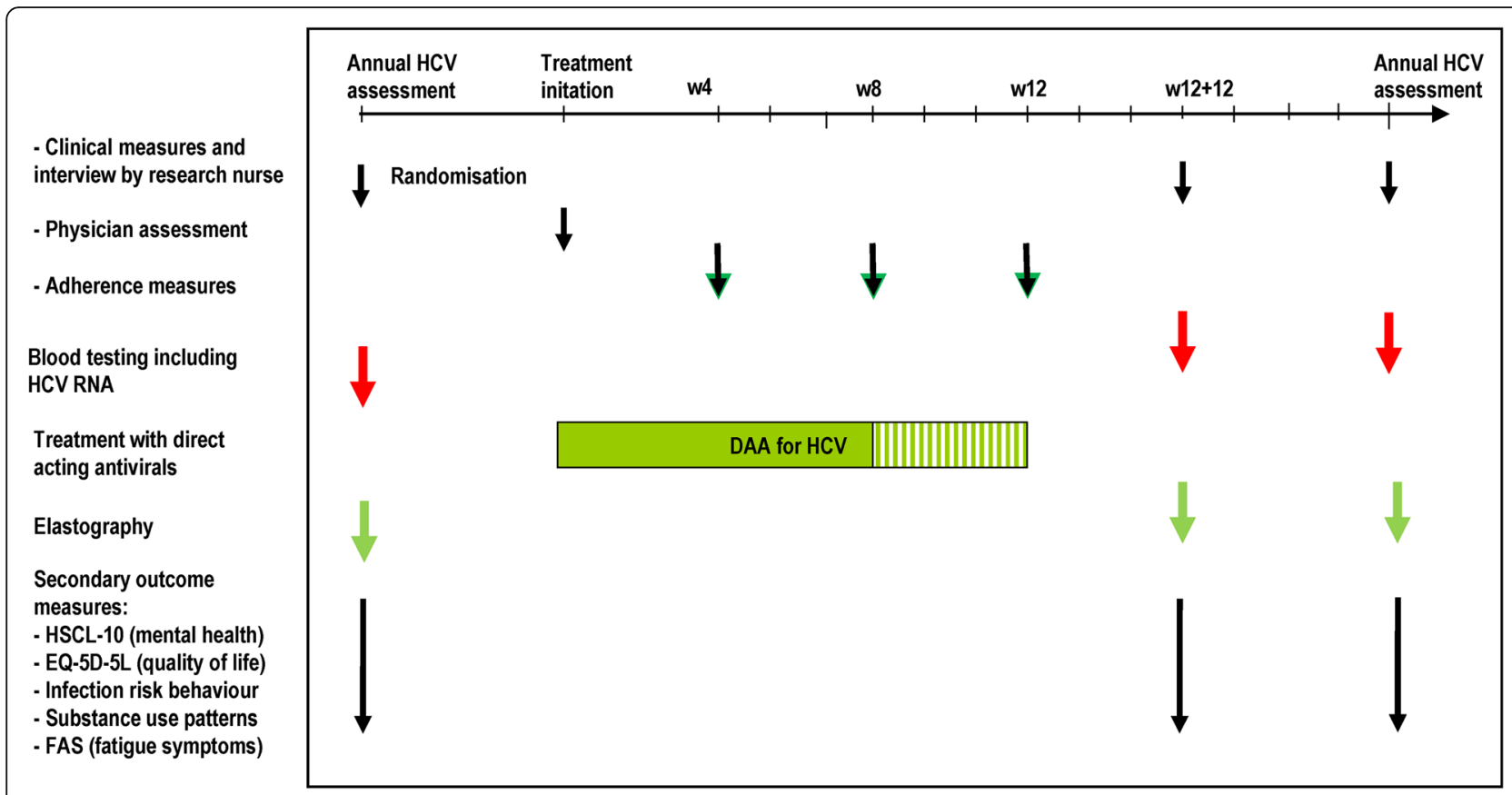

Fig. 1 Overview of follow-up for the study * The arrows are indications of when the various measured are timed

an observational study assessing $\mathrm{HCV}$ reinfections, other infections including HIV, and liver disease severity.

Our trial involves some limitations and several strengths. For the trial it is difficult to ensure complete blinding, however, we will aim for blinding of data collectors and some degree of blinding for participants. The study is also funded from public sources ensuring independency. We also have a biological primary outcome. Thus, substantial information biases are considered unlikely. The study is individually randomised minimizing potential confounding. The study population of PWID will include a large proportion struggling to obtain standard care. This will not be applicable to all groups of people with substance use disorders. For people with substance use disorders with higher levels of functioning and less need for regular treatment follow-up, the need for treatment integration might not be as relevant. The study setting is also very suitable to test out treatment integration. The time prior to change in the national guidelines for treatment of $\mathrm{HCV}$ made it necessary for some people to delay $\mathrm{HCV}$ treatment initiation. This might impact negatively on the treatment outcomes, but probably is balanced between the arms. Further, most of the participants will be treated after the guideline changes where treatment is now available independent of stage of liver fibrosis. Subsequently, we assume that this effect will not be substantial. The study might be well suited to assess some biological effects of $\mathrm{HCV}$ infection such as to which extent $\mathrm{HCV}$ contributes to fatigue, reduced quality of life, occurrence of mental disorders and continued drug use. The study size should be sufficient to answer the primary objectives with high precision and is assumed to have adequate precision also for secondary objectives. In terms of safety, the frequent follow-up of PWID could improve detection of potential adverse effects of the applied medications. One can see trials on a continuity from efficacy trials optimising internal validity through homogeneous population to effectiveness trials optimising external validity with a more heterogeneous population. This trial is tending towards the effectiveness side of the spectrum. An alternative design could have been a stepped-wedge trial which could have required slightly smaller sample sizes and would also be well opted to measure effectiveness of integrated treatment. However, we expect to have enough participants to meet the sample size requirements. On the other side, stepped-wedged trials generally take longer time to conduct due to the time delay. In addition, our more conventional trial design is less vulnerable to confounding from time trends.

Our assessment will also inform future health policy on efficiency by using standard methods of costeffectiveness analysis taking both the expected effectiveness and provider costs of the intervention into consideration. Even though there is evidence on the costeffectiveness of standard DAA in HCV treatment regimens; there is limited evidence for the cost-effectiveness 
of alternative scale-up scenarios taking the complex behavior of PWID into account [27].

If the integrated treatment model for $\mathrm{HCV}$ in clinics for PWID compared to standard care is found to be safe and efficacious in terms of increasing access and improving treatment outcomes, this model could be considered for further scale-up.

\section{Abbreviations}

DAA: Direct-acting antiviral treatment; HCV: Hepatitis C virus; OAT: Opioid agonist therapy; PWID: People who inject drugs; QALY: Quality Adjusted Life Year; SAE: Severe adverse effects; SVR: ustained virologic response

\section{Acknowledgements}

We thank the devoted clinical staff for their enthusiasm during the planning of the project. We also thank Nina Elisabeth Eltvik and Christer Kleppe for valuable help and input during the planning and preparation phases. INTRO-HCV Study Group participating investigators:

Bergen: Christer Frode Aas, Vibeke Bråthen Buljovcic, Fatemeh Chalabianloo, Jan Tore Daltveit, Silvia Eiken Alpers, Lars T. Fadnes (principal investigator), Trude Fondenes Eriksen, Per Gundersen, Velinda Hille, Kristin Holmelid Håberg, Kjell Arne Johansson, Rafael Alexander Leiva, Siv-Elin Leirvåg Carlsen, Martine Lepsøy Bonnier, Lennart Lorås, Else-Marie Løberg, Mette Hegland Nordbotn, Cathrine Nygård, Maria Olsvold, Christian Ohldieck, Lillian Sivertsen, Hugo Torjussen, Jørn-Henrik Vold, Jan-Magnus Økland. Stavanger: Tone Lise Eielsen, Nancy Laura Ortega Maldonado, Ewa Joanna Wilk.

proLAR: Ronny Bjørnestad, Ole Jørgen Lygren, Marianne Cook Pierron. Oslo: Olav Dalgard, Håvard Midgard, Svetlana Skurtveit. Bristol: Peter Vickerman.

\section{Authors' contributions}

All authors (LTF, CFA, JHV, CO, AL, FC, SS, OJL, OD, PV, HM, EML and KAJ) have been involved in design of the study, contributed to implementation and writing of the protocol.

\section{Funding}

The study was funded by The Norwegian Research Council (BEHANDLING, contract no 269855) and the Western Norway Regional Health Authority («Åpen prosjektstøtte») with Department of Addiction Medicine, Haukeland University Hospital as responsible institution. The funders had no role in study design, data collection and analysis, decision to publish, or preparation of the manuscript.

\section{Availability of data and materials}

Trial outcome data is not yet available.

\section{Competing interest}

The authors LTF, CFA, JHV, SS, CO, FC, EML, KAJ, have no competing interests. AL has received lecture and advisory fees from Gilead, GSK and MSD. OD has received research grants from and been in advisory board for MSD, Abbvie and Gilead. PV has received an unrestricted research grant off Gilead. HM has received lecture and advisory fees from Gilead, Abbvie and MSD.

\section{Ethics approval and consent to participate}

Except from use of a few hours of time from the participants and possible discomfort related to examinations such as blood sample collection, participation is not believed to be linked with substantial risks.

The study has been approved by regional ethical committee (no. 2017/51/ REK Vest, dated 29.03.2017/20.04.2017). The trial will be conducted in strict accordance with the Declaration of Helsinki and other international conventions and with GCP and GLP standards [28, 29]. Written informed consent and assent will be obtained from each participant.

\section{Consent for publication}

All authors have consented for publication.

\section{Author details}

Bergen Addiction Research Group, Department of Addiction Medicine, Haukeland University Hospital, Bergen, Norway. ${ }^{2}$ Department of Global Public Health and Primary Care, University of Bergen, Bergen, Norway. ${ }^{3}$ Department of Medicine, Haukeland University Hospital, Bergen, Norway. ${ }^{4}$ Norwegian Centre for Addiction Research, University of Oslo, Oslo, Norway. ${ }^{5}$ Department of Mental Disorders, Norwegian Institute of Public Health, Oslo, Norway. ${ }^{6}$ ProLAR Nett, Oslo, Norway. ${ }^{7}$ Department of Infectious Diseases, Akershus University Hospital, Lørenskog, Norway. ${ }^{8}$ Institute for Clinical Medicine, University of Oslo, Oslo, Norway. ${ }^{9}$ University of Bristol, Bristol, UK.

${ }^{10}$ Department of Gastroenterology, Oslo University Hospital, Oslo, Norway.

${ }^{11}$ Department of Clinical Psychology Medicine, University of Bergen, Bergen, Norway. ${ }^{12}$ Division of Psychiatry, Haukeland University Hospital, Bergen, Norway.

Received: 1 April 2019 Accepted: 25 October 2019

Published online: 08 November 2019

\section{References}

1. Degenhardt L, Charlson F, Stanaway J, Larney S, Alexander LT, Hickman M Cowie B, Hall WD, Strang J, Whiteford $\mathrm{H}$, et al. Estimating the burden of disease attributable to injecting drug use as a risk factor for HIV, hepatitis $C$, and hepatitis B: findings from the global burden of disease study 2013. Lancet Infect Dis. 2016;16(12):1385-98.

2. Grebely J, Larney S, Peacock A, Colledge S, Leung J, Hickman M, Vickerman $P$, Blach S, Cunningham EB, Dumchev K, et al. Global, regional, and countrylevel estimates of hepatitis $C$ infection among people who have recently injected drugs. Addiction. 2019;114(1):150-66.

3. Seeff LB. Natural history of chronic hepatitis C. Hepatology. 2002;36(5 Suppl 1):S35-46.

4. Hajarizadeh B, Grebely J, Dore GJ. Epidemiology and natural history of HCV infection. Nat Rev Gastroenterol Hepatol. 2013;10(9):553-62.

5. Kielland KB, Delaveris GJ, Rogde S, Eide TJ, Amundsen EJ, Dalgard O. Liver fibrosis progression at autopsy in injecting drug users infected by hepatitis C: a longitudinal long-term cohort study. J Hepatol. 2014;60(2):260-6.

6. Kielland KB, Skaug K, Amundsen EJ, Dalgard O. All-cause and liver-related mortality in hepatitis $C$ infected drug users followed for 33 years: a controlled study. J Hepatol. 2013;58(1):31-7.

7. Waal H, Bussesund K, Clausen T, Skeie I, Håseth A, Lillevold PH: RAPPORT 1/ 2016: Statusrapport 2015. Mot grensene for vekst og nytte? In., vol. 1: Universitetet i Oslo, Oslo Universitetssykehus, Senter for rus- og avhengighetsforskning (SERAF). 2016: 127.

8. Waal H, Bussesund K, Clausen T, Lillevold PH, Skeie I: RAPPORT 3/2018: Statusrapport 2017. LAR 20 år. Status, vurderinger og perspektiver. In., vol. 1: Universitetet i Oslo, Oslo Universitetssykehus, Senter for rus- og avhengighetsforskning (SERAF). 2018: 127.

9. Midgard H, Weir A, Palmateer N, Lo Re V 3rd, Pineda JA, Macias J, Dalgard O. HCV epidemiology in high-risk groups and the risk of reinfection. J Hepatol. 2016;65(1 Suppl):S33-45.

10. Midgard H, Bramness JG, Skurtveit S, Haukeland JW, Dalgard O. Hepatitis C treatment uptake among patients who have received opioid substitution treatment: a population-based study. PLoS One. 2016;11(11):e0166451.

11. World Hepatitis Summit in São Paulo (Brazil): São Paulo Declaration on Viral Hepatitis from World Hepatitis Summit 1-3 November 2017. In. World health Organization; 2017: 3.

12. Mravcik V, Strada L, Stolfa J, Bencko V, Groshkova T, Reimer J, Schulte B. Factors associated with uptake, adherence, and efficacy of hepatitis $C$ treatment in people who inject drugs: a literature review. Patient Prefer Adherence. 2013:7:1067-75.

13. Iversen J, Grebely J, Topp L, Wand H, Dore G, Maher L. Uptake of hepatitis C treatment among people who inject drugs attending needle and syringe programs in Australia, 1999-2011. J Viral Hepat. 2014;21(3):198-207.

14. Lindenburg CE, Lambers FA, Urbanus AT, Schinkel J, Jansen PL, Krol A, Casteelen G, van Santen G, van den Berg CH, Coutinho RA, et al. Hepatitis C testing and treatment among active drug users in Amsterdam: results from the DUTCH-C project. Eur J Gastroenterol Hepatol. 2011;23(1):23-31.

15. Grebely J, Bruneau J, Lazarus JV, Dalgard O, Bruggmann P, Treloar C, Hickman M, Hellard M, Roberts T, Crooks L, et al. Research priorities to achieve universal access to hepatitis $C$ prevention, management and directacting antiviral treatment among people who inject drugs. Int J Drug Policy. 2017:47:51-60 
16. Vold JH, Aas CF, Leiva RAM, Vickerman P, Chalabianloo F, Løberg E-M, Johansson KA, Fadnes LT. Integrated care of severe infectious diseases to people with substance use disorders; a systematic review. BMC Infect Dis. 2019:19:306.

17. Hjellum K, Wåde-Engelsen M: BrukerPlan 2015: En kartlegging av kommunale tjenestemottakere over 18 år med psykiske problem, rusrelaterte problem, eller samtidige rus- og psykiske problem (ROP). In.: Bergen kommune; 2016.

18. Chou R, Wasson N. Blood tests to diagnose fibrosis or cirrhosis in patients with chronic hepatitis $C$ virus infection: a systematic review. Ann Intern Med. 2013;158(11):807-20.

19. Lin ZH, Xin YN, Dong QJ, Wang Q, Jiang XJ, Zhan SH, Sun Y, Xuan SY. Performance of the aspartate aminotransferase-to-platelet ratio index for the staging of hepatitis C-related fibrosis: an updated meta-analysis. Hepatology. 2011;53(3):726-36.

20. Ferenci P, Lockwood A, Mullen K, Tarter R, Weissenborn K, Blei AT. Hepatic encephalopathy--definition, nomenclature, diagnosis, and quantification: final report of the working party at the 11th world congresses of gastroenterology, Vienna, 1998. Hepatology. 2002;35(3):716-21.

21. Dal-Re $R$, Janiaud $P$, loannidis JPA. Real-world evidence: how pragmatic are randomized controlled trials labeled as pragmatic? BMC Med. 2018;16(1):49.

22. Moher D, Schulz KF, Altman DG. The CONSORT statement: revised recommendations for improving the quality of reports of parallel-group randomised trials. Lancet. 2001;357(9263):1191-4.

23. Welch VA, Norheim OF, Jull J, Cookson R, Sommerfelt H, Tugwell P, Equity C, Boston Equity S. CONSORT-Equity 2017 extension and elaboration for better reporting of health equity in randomised trials. Bmj. 2017;359:j5085.

24. SPIRIT Statement [http://www.spirit-statement.org/].

25. European Association for Study of L. EASL recommendations on treatment of hepatitis C 2015. J Hepatol. 2015;63(1):199-236.

26. Mucke MM, Backus LI, Mucke VT, Coppola N, Preda CM, Yeh ML, Tang LSY, Belperio PS, Wilson EM, Yu ML, et al. Hepatitis B virus reactivation during direct-acting antiviral therapy for hepatitis $\mathrm{C}$ : a systematic review and metaanalysis. Lancet Gastroenterol Hepatol. 2018;3(3):172-80.

27. Selvapatt N, Ward T, Harrison L, Lombardini J, Thursz M, McEwan P, Brown A: The cost impact of outreach testing and treatment for hepatitis $C$ in an urban drug treatment unit. Liver Int 2016.

28. EAEMP: European Agency for Evaluation of medical products. Guidelines for clinical practice. Including errata. In.; 2002.

29. OECD: List of OECD series on principles on good laboratory practice and compliance monitoring (documents 1 to 13). In.; 1998.

\section{Publisher's Note}

Springer Nature remains neutral with regard to jurisdictional claims in published maps and institutional affiliations.

Ready to submit your research? Choose BMC and benefit from:

- fast, convenient online submission

- thorough peer review by experienced researchers in your field

- rapid publication on acceptance

- support for research data, including large and complex data types

- gold Open Access which fosters wider collaboration and increased citations

- maximum visibility for your research: over $100 \mathrm{M}$ website views per year

At $\mathrm{BMC}$, research is always in progress.

Learn more biomedcentral.com/submissions 